\title{
Occupational blood exposure beyond needle stick injuries: hospital-based cross-sectional study among healthcare workers in governmental hospitals of Northern Ethiopia
}

Semere Reda ${ }^{1 \dagger}$, Mesfin Gebrehiwot $^{1^{* \dagger}} \mathbb{B}$, Mistir Lingerew ${ }^{1}$, Awoke Keleb ${ }^{1}$, Tefera chane Mekonnen ${ }^{2}$, Birhanu Wagaye ${ }^{2}$, Amanuel Atamo', Chala Daba', Alelgne Feleke ${ }^{1}$ and Metadel Adane ${ }^{1}$

\begin{abstract}
Background: Occupational blood exposure is one of the major public health problems that healthcare workers (HCWs) are encountering. Most previous occupational blood exposure studies are delimited to needle stick injury, which could underestimate the real level of blood exposure. On the other hand, others deal with crude blood and body-fluids exposure, which possibly overestimate the magnitude of blood exposure. Therefore, this study aimed at determining the prevalence of occupational blood exposure and identifying associated factors among HCWs in the Southern Tigrai zone governmental hospitals of Northern Ethiopia considering all the potential means of blood exposure (needle stick injury, sharp medical equipment injury, and blood splash) while excluding blood-free bodyfluids.
\end{abstract}

Methods: A hospital based cross-sectional study design was employed to gather data from randomly selected HCWs in three governmental hospitals from February to March, 2020. A multivariable logistic regression model was used to identify the independent factors associated with the outcome variable.

Results: From the total of $318 \mathrm{HCWs}, 148$ (46.5\%) were exposed to blood at least once in their lifetime. Working for more than $40 \mathrm{~h}$ per week ( $\mathrm{AOR}=9.4 ; 95 \% \mathrm{Cl}$ : 7.61, 11.41), lack of adequate personal protective equipment (PPE) ( $A O R=3.88 ; 95 \% \mathrm{Cl}: 1.64,5.42$ ), Hepatitis B virus vaccination ( $\mathrm{AOR}=0.54 ; 95 \% \mathrm{Cl}: 0.12,0.78$ ), recapping used needle sticks (AOR=3.18; $95 \% \mathrm{Cl}: 1.28,8.83$ ), and lack of infection prevention and patient safety (IPPS) training (AOR=13.5; $95 \%$ Cl: 8.12,19.11) were detected to significantly increase the likelihood of occupational blood exposure.

Conclusions: As nearly half of the HCWs were exposed to blood, reducing work load below $40 \mathrm{~h}$ per week by employing additional staff members, supplying adequate PPE, avoiding recapping of used needle sticks, and providing IPPS training for the HCWs should be practiced.

Keywords: Healthcare workers, Occupational exposure, Infection control, Ethiopia

\footnotetext{
* Correspondence: gebrehiwotmesfin@yahoo.com

'Department of Environmental Health, College of Medicine and Health Sciences, Wollo University, Dessie, Ethiopia

Full list of author information is available at the end of the article
} 


\section{Background}

Occupational blood exposure is one of the major public health problems that healthcare workers (HCWs) are encountering. Unintended exposure to blood might carry the risk of infection by various blood-borne viruses including Hepatitis B virus (HBV), Hepatitis C virus (HCV), and Human immunodeficiency virus (HIV). No matter how occupational blood exposure is a global issue, the problem is worsening in developing countries in which safety practices and protective devices are not properly utilized [1].

HCWs who experience occupational blood exposure also go through some kinds of psychiatric problems, such as depression and associated post-traumatic stress disorder. The consequences of these effects include absenteeism and poor quality of healthcare service delivery to the community [2].

The World Health Organization (WHO) estimates that among 35 million HCWs worldwide, three million experience occupational blood exposure each year. As a result of these exposures, $150,000 \mathrm{HCWs}$ get infected to $\mathrm{HCV}, 70,000$ to $\mathrm{HBV}$, and 500 to HIV per year. More than $90 \%$ of these infections occurs in developing countries, particularly in sub-Saharan Africa [3]. A systematic review done on the occupational exposures of HCWs to body fluids in 21 African countries showed that the lifetime and one-year blood exposure were $5.7 \%$ and $48 \%$, respectively [4]. A serious blood-borne infection can cost more than a million dollar in medication, follow up, laboratory testing, clinical evaluation, lost wage, and disability payments. The estimated annual cost due to blood exposure could be 6-7 million dollars in Spain and 4-300 million euros in England. This estimation is based on the reported number of needle stick injuries in different countries and the exact cost still cannot be estimated as large numbers of incidents remain unreported [5].

The Ethiopian federal ministry of health has tried to reform hospitals throughout the country following the "Ethiopian hospitals reform implementation guideline and infection prevention and patient safety strategy" with the prime aim of reducing occupational blood exposure and associated healthcare-acquired infections [6]. Despite the efforts, the prevalence of one-year and lifetime needle stick injuries among the Ethiopian HCWs is as high as $55.1 \%$ and $63.6 \%$, respectively [7]. Of course, occupational exposures to blood and other body fluids could vary among different regions of the country [8]. The provision of protective equipment, safety trainings and the number of healthcare workforce are indicated to have significant implications for occupational exposures $[7,9]$. On top of that, there is poor compliance to infection prevention practices among HCWs [10].

Though there are some studies regarding occupational blood exposure, most of them are delimited to needle stick injury, which could underestimate the real occupational blood exposure burden for HCWs $[11,12]$. On the other hand, others deal with crude blood and body-fluids exposure, which possibly overestimate the blood exposure burden [9, 13]. Therefore, considering all means of blood exposure, including needle stick injury, sharp medical equipment injury, and blood splash while excluding blood-free body-fluids will give a better estimate of occupational blood exposure. This study, hence, aimed at assessing the prevalence of occupational blood exposure and associated factors among HCWs in the Southern Tigrai zone governmental hospitals of Northern Ethiopia.

\section{Materials and methods Study design and area}

A hospital-based cross-sectional study design was employed from February to March, 2020. The study was conducted in the Southern Tigrai zone of Ethiopia, which is located some $665 \mathrm{~km}$ north of the Ethiopian capital, Addis Ababa. Based on the 2019 population projection, Southern Tigrai zone has a total population of 826,042 , of whom 404,761 are men and 421,281 are women [14]. According to the Southern Tigrai zone health office report of 2019, there are five governmental hospitals with a total of 834 HCWs.

\section{Source population, study population, and study unit}

All the 834 HCWs in the Southern Tigrai zone governmental hospitals were the source population. The study population includes all the $574 \mathrm{HCWs}$ in the randomly selected Southern Tigrai Zone governmental hospitals. The randomly selected and interviewed HCWs were the study units.

\section{Inclusion and exclusion criteria}

All healthcare professionals (nurses, midwives, physicians, surgeons, laboratory technicians, health officers, anesthetics, dentists, and environmental health officers) and selected supportive staff (i.e., cleaners and laundry workers) who had the chance of direct contact with patients' blood were included in the study. However, newly recruited and transferred HCWs who did not start their job by any reason were excluded from the study.

\section{Sample size determination}

The sample size was calculated by using single population proportion formula. A $5 \%$ margin of error (d), $95 \%$ confidence level (alpha, $\alpha=0.05$ two-tailed), and $28 \%$ proportion were assumed. Accordingly, the total sample size was calculated as:

$$
\begin{aligned}
& n=\frac{(Z \alpha / 2)^{2} p(1-p)}{d^{2}} \\
& n=\frac{(1.96)^{2}(0.28)(1-0.28)}{(0.05)^{2}}=309
\end{aligned}
$$


Where,

$n=$ required sample size.

$Z=$ critical value for normal distribution at $95 \%$ confidence level ( $Z$ value at $\alpha 0.05$, two tailed $=1.96$ ).

$P=28 \%$ prevalence of occupational blood exposure [15].

\section{$d=5 \%$ margin of error.}

As the study followed two stages of sampling, a design effect of 1.5 was considered. Accordingly, the total sample size was $464(309 \times 1.5)$. Since sampling was from a finite population $(N=834)$ and as the calculated sample size was more than sufficient to represent the source population, we employed finite population correction. Therefore, the final sample size was calculated as:

$$
n f=\frac{\mathrm{n}}{1+\mathrm{n} / \mathrm{N}}=298
$$

Where,

$n$ = calculated sample size before sample size correction (464).

$N=$ total number of HCWs in the Southern Tigrai zone hospitals (834).

$n f=$ final corrected sample size.

By considering a $10 \%$ non-response rate, the total sample size for this study was $328 \mathrm{HCWs}$.

\section{Sampling procedure}

From the five governmental hospitals in the Southern Tigrai zone, three hospitals (Alamata general hospital, Lemlem Karl general hospital, and Mehoni primary hospital) were selected using lottery method. Then, proportional allocation of samples was made to the selected hospitals based on the total number of HCWs in each hospital. The study units were grouped into seven based on their profession category (i.e., Nurse, Midwifery, Medical doctor, Cleaner, Laboratory, Laundry, and others). Proportional allocation was made again to each profession considering their total number. Accordingly, from each profession, about $57 \%$ study participants were included. This represents about $40 \%$ of the source population. Finally, by using the list of the HCWs from monthly payroll as a sampling frame, simple random sampling technique was used to select 328 study participants.

\section{Data collection technique}

A questionnaire was developed by reviewing pieces of literature of similar studies on occupational blood exposure. First, the questionnaire was prepared in English, and then translated into the local Amharic and Tigrigna languages. The questionnaire has four parts, namely socio-economic and demographic characteristics, institutional characteristics, behavioral and training related characteristics, and blood exposure status information (Appendix A). Data was collected using face to face interview and observation. A HCW was categorized as exposed if he/she had a history of needle stick injury, sharp injury, and/or blood splash in the course of their work [16].

\section{Data quality assurance}

Data quality assurance was in place during questionnaire design, data collection, entry, and analysis. The questionnaire was objective-based, logically sequenced, free of scientific terms, and non-leading. The questionnaire was also pre-tested on $5 \%$ of the sample size $(n=16)$ in the neighboring general hospital (Quiha hospital). Based on the pre-test, whenever necessary, the questions were revised, edited, and those found to be unclear or confusing were modified.

Three data collectors and two supervisors were recruited and trained for one day about the study instrument and data collection procedures. Each questionnaire was checked for completeness before winding up the visit to each study participant. Completed questionnaires were checked daily for completeness, legibility, and consistency. Continuous follow-up and supervision were also made by the principal investigator and supervisors throughout the data collection period.

\section{Data analysis}

The collected data was entered into EpiData 3.1 and then exported into SPSS 21.0 for data cleaning and analysis. After cleaning the data for internal consistency, descriptive statistics, such as frequency and percentage were calculated to see the overall distribution of the study variables. In order to identify factors associated with occupational blood exposure, first, bivariable logistic regression analysis with $p<0.25$ was performed to screen candidate variables. Then, a multivariable analysis was used to control possible confounders. Adjusted odds ratio (AOR) and their $95 \% \mathrm{CI}$ were used to measure the association between dependent and independent variables. A significance level of $p<0.05$ was used to decide the significance of statistical tests. Multi-collinearity among the independent variables was carried out using standard error. As the maximum standard error was 1.95, there was no multicollinearity. The model fitness was checked by Hosmer-Lemeshow test and $p>0.05$ was considered.

\section{Ethical considerations}

All methods, including ethical approval and research permission, were performed in accordance with national standards, guaranteeing the anonymity of the respondents. The study was approved by the institutional review board of Wollo University, college of medicine and health sciences (WU/CMHS/1129/02/12). In addition, written consents were obtained from the Southern 
Tigrai zone coordinator and from the selected hospitals. Besides, respondents were informed about the purpose of the study, and their informed consent was obtained. The respondents' right to refuse or withdraw from the study was fully maintained and the information provided by each respondent was kept strictly confidential.

\section{Results}

\section{Socio-economic and demographic characteristics}

A total of $328 \mathrm{HCWs}$ have participated in this study. From them, $318 \mathrm{HCWs}$ provided complete information giving a response rate of $97 \%$. Among the respondents, $193(60.7 \%)$ were females. The age range of the study subjects was from 20 to 54 years with the mean $( \pm$ SD) age of $29.4 \pm 5.4$ years. By profession, 117 (36.8\%) of them were nurses followed by midwives (17\%) and cleaners $(14.5 \%)$, respectively (Table 1$)$. Regarding their educational status, more than half $(182,57.2 \%)$ of the HCWs obtained a bachelor degree. Among the study participants, the majority $(74.8 \%)$ had five years or less work experience (Table 1).

\section{Institutional characteristics}

From the total of $318 \mathrm{HCWs}, 180$ (56.6\%) were working more than $40 \mathrm{~h}$ per week and 142 (44.7\%) had no work time shift. Furthermore, 101 (31.8\%) HCWs had additional responsibilities inside the institution and 92 $(28.9 \%)$ were working in private clinics in addition to their routine institutional activities. Unfortunately, about half $(49.7 \%)$ of the respondents reported the lack of PPE in the last 12 months and $218(68.6 \%)$ HCWs have received HBV vaccination. Moreover, 223 (70.1\%) and 42 (13.2\%) had no emergency shower and functional hand washing tap in their working rooms, respectively (Table 2).

Behavioral characteristics and training related information From the total respondents, 144 (37.7\%) HCWs had needle recapping behavior. In addition, 25 (7.9\%), 8 $(2.5 \%)$, and 16 (5\%) of the respondents had alcoholdrinking, Khat chewing, and cigarette smoking behaviors, respectively. Concerning training experiences, 266 $(83.6 \%)$ and $256(80.5 \%)$ HCWs were not trained about IPPS and healthcare waste management, respectively (Table 3).

\section{Prevalence of occupational blood exposure and related information}

In this study, 148 (46.5\%) of the HCWs were exposed to blood at least once in their lifetime (95\% CI: $41 \%-52 \%$ ). The main route of blood exposure was through blood
Table 1 Socio-economic and demographic characteristics of HCWs $(N=318)$ in the Southern Tigrai zone governmental hospitals, Northern Ethiopia, 2020

\begin{tabular}{|c|c|c|c|}
\hline Variables & Category & Frequency (n) & Percent (\%) \\
\hline \multirow[t]{5}{*}{ Age (years) } & $\leq 25$ & 67 & 21.1 \\
\hline & $26-30$ & 152 & 47.8 \\
\hline & $31-35$ & 68 & 21.4 \\
\hline & $36-40$ & 17 & 5.3 \\
\hline & $>40$ & 14 & 4.4 \\
\hline \multirow[t]{2}{*}{ Sex } & Male & 125 & 39.3 \\
\hline & Female & 193 & 60.7 \\
\hline \multirow[t]{4}{*}{ Marital status } & Single & 117 & 36.8 \\
\hline & Married & 165 & 51.9 \\
\hline & Divorced & 29 & 9.1 \\
\hline & Widowed & 7 & 2.2 \\
\hline \multirow[t]{7}{*}{ Profession } & Nurse & 117 & 36.8 \\
\hline & Midwife & 54 & 17.0 \\
\hline & Laboratory & 30 & 9.4 \\
\hline & Medical doctor & 33 & 10.4 \\
\hline & Cleaner & 46 & 14.5 \\
\hline & Laundry & 25 & 7.9 \\
\hline & ${ }^{*}$ Others & 13 & 4.1 \\
\hline \multirow[t]{5}{*}{ Educational status } & Below diploma & 50 & 16.0 \\
\hline & Diploma & 50 & 16.0 \\
\hline & BSc degree & 182 & 57.3 \\
\hline & Medical doctor & 27 & 8.5 \\
\hline & Specialty & 9 & 2.2 \\
\hline \multirow[t]{3}{*}{ Work experience (years) } & $\leq 5$ & 238 & 74.8 \\
\hline & $6-10$ & 61 & 19.2 \\
\hline & $>10$ & 19 & 6.0 \\
\hline \multirow[t]{4}{*}{ Monthly income (ETB) } & $\leq 2000$ & 72 & 22.6 \\
\hline & $2001-3500$ & 32 & 10.1 \\
\hline & $3501-5000$ & 95 & 29.9 \\
\hline & $>5000$ & 119 & 37.4 \\
\hline
\end{tabular}

*Others (Anesthesia, Environmental health officer, Radiologist, Psychiatrist, Physiotherapist, Health officer, Maintenance worker, Ophthalmic nurse, and Dentist), ETB-Ethiopian birr

splash (67.6\%) followed by needle stick injury (36.5\%), and sharp injury (19.6\%). From the exposed HCWs, 47 $(31.8 \%)$ of them were exposed at the delivery ward followed by at the operation theater unit $(40,27 \%)$. Moreover, among the exposed respondents, 83 (56.1\%) did not report the exposure to the concerned body (Table 4).

Factors associated with occupational blood exposure While running the bivariable logistic regression analysis, profession, level of the hospital, working hours per week, 
Table 2 Institutional characteristics of HCWs (N=318) in the Southern Tigrai zone governmental hospitals, Northern Ethiopia, 2020

\begin{tabular}{|c|c|c|c|}
\hline Variables & Category & Frequency (n) & Percent (\%) \\
\hline \multirow[t]{2}{*}{ Level of the hospital } & Primary & 80 & 25.2 \\
\hline & General & 238 & 74.8 \\
\hline \multirow[t]{2}{*}{ Working hours per week } & $\leq 40$ & 138 & 43.4 \\
\hline & $>40$ & 180 & 56.6 \\
\hline \multirow[t]{2}{*}{ Working time shift } & No & 142 & 44.7 \\
\hline & Yes & 176 & 55.3 \\
\hline \multirow[t]{2}{*}{ Additional responsibilities inside the institution } & No & 217 & 68.2 \\
\hline & Yes & 101 & 31.8 \\
\hline \multirow[t]{2}{*}{ Work in private clinics } & No & 226 & 71.1 \\
\hline & Yes & 92 & 28.9 \\
\hline \multirow[t]{2}{*}{${ }^{1}$ Adequate PPE supply in the last 12 months } & No & 158 & 49.7 \\
\hline & Yes & 160 & 50.3 \\
\hline \multirow[t]{2}{*}{ Universal safety guideline /protocol in working room } & No & 67 & 21.1 \\
\hline & Yes & 251 & 78.9 \\
\hline \multirow[t]{2}{*}{ Presence of functional IPPS committee } & No & 168 & 52.8 \\
\hline & Yes & 150 & 47.2 \\
\hline \multirow[t]{2}{*}{ Presence of emergency shower } & No & 223 & 70.1 \\
\hline & Yes & 95 & 29.9 \\
\hline \multirow[t]{2}{*}{ Presence of functional hand washing tap } & No & 42 & 13.2 \\
\hline & Yes & 276 & 86.8 \\
\hline \multirow[t]{2}{*}{ Three color coded dust bins } & No & 83 & 26.1 \\
\hline & Yes & 235 & 73.9 \\
\hline \multirow[t]{2}{*}{ Morning session about occupational blood exposure } & No & 177 & 55.7 \\
\hline & Yes & 141 & 44.3 \\
\hline \multirow[t]{2}{*}{ Functional laundry machine } & No & 192 & 60.4 \\
\hline & Yes & 126 & 39.6 \\
\hline \multirow[t]{2}{*}{ Adequate safety box in the last 12 months } & No & 105 & 33.0 \\
\hline & Yes & 140 & 44.0 \\
\hline \multirow[t]{2}{*}{ HBV vaccination } & No & 100 & 31.4 \\
\hline & Yes & 218 & 68.6 \\
\hline \multirow[t]{11}{*}{ Working department } & Emergency and injection room & 16 & 5.0 \\
\hline & Pediatrics ward & 25 & 7.9 \\
\hline & Delivery ward & 55 & 17.3 \\
\hline & Medical ward & 18 & 5.7 \\
\hline & Surgical ward & 14 & 4.4 \\
\hline & Operation theater unit & 25 & 7.9 \\
\hline & Cleaner unit & 45 & 14.2 \\
\hline & Laundry unit & 23 & 7.2 \\
\hline & Laboratory unit & 24 & 7.5 \\
\hline & OPD & 39 & 12.3 \\
\hline & *Others & 34 & 10.7 \\
\hline
\end{tabular}

${ }^{1}$ Adequate PPE supply indicates availability of sufficient personal protective equipment whenever required by the healthcare workers, IPPS- Infection prevention and patient safety, ${ }^{*}$ Others (Abortion, MCH, ART, and TB rooms), PPE- personal protective equipment, HBV- Hepatitis B Virus, OPD-outpatient department) 
Table 3 Behavioral characteristics and training related information of HCWs $(N=318)$ in the Southern Tigrai zone governmental hospitals, Northern Ethiopia, 2020

\begin{tabular}{|c|c|c|c|}
\hline Variables & Category & Frequency (n) & Percent (\%) \\
\hline \multirow[t]{2}{*}{ PPE use before any procedure } & No & 150 & 47.2 \\
\hline & Yes & 168 & 52.8 \\
\hline \multirow[t]{2}{*}{ Following standard procedures } & No & 62 & 19.5 \\
\hline & Yes & 256 & 80.5 \\
\hline \multirow[t]{2}{*}{ Recapping used needle sticks } & No & 174 & 45.2 \\
\hline & Yes & 144 & 37.7 \\
\hline \multirow[t]{2}{*}{ Alcohol drinking } & No & 293 & 92.1 \\
\hline & Yes & 25 & 7.9 \\
\hline \multirow[t]{2}{*}{ Khat chewing } & No & 310 & 97.5 \\
\hline & Yes & 8 & 2.5 \\
\hline \multirow[t]{2}{*}{ Cigarette smoking } & No & 302 & 95.0 \\
\hline & Yes & 16 & 5.0 \\
\hline \multirow[t]{2}{*}{${ }^{1}$ Proper waste segregation practice } & No & 55 & 17.3 \\
\hline & Yes & 263 & 82.7 \\
\hline \multirow[t]{2}{*}{ Lifetime training on IPPS } & No & 266 & 83.6 \\
\hline & Yes & 52 & 16.4 \\
\hline \multirow[t]{2}{*}{ Lifetime training on healthcare waste management } & No & 256 & 80.5 \\
\hline & Yes & 62 & 19.5 \\
\hline
\end{tabular}

${ }^{1}$ proper waste segregation practice was noted whenever waste materials were disposed separately based on the provided color coded dust bins (observation), PPE- Personal protective equipment, IPPS- Infection prevention and patient safety

working time shift, involved in additional responsibilities, adequate PPE supply, safety box supply, needle recapping behavior, vaccination status, proper waste segregation practice, and IPPS training were the candidate variables with $p<0.25$. These variables were then considered for the multivariate logistic model so as to screen variables that have statistically significant association with blood exposure (Table 5).

In the multivariable logistic regression analysis, working hours per week, lack of PPE supply, needle recapping behavior, vaccination status, and lack of IPPS training showed statistically significant association with occupational blood exposure at $p<0.05$ (Table 5). The analysis indicated that HCWs who work for more than $40 \mathrm{~h}$ per week were $9.42(\mathrm{AOR}=9.42$; $95 \% \mathrm{CI}$ : 7.61, 11.41) times more likely to be occupationally exposed to blood than those who work for less than $40 \mathrm{~h}$ per week. Similarly, those HCWs who do not have adequate supply of PPE had an odds of 3.88 (AOR=3.88; $95 \%$ CI: $1.64,5.42)$ to be occupationally exposed to blood than others. Moreover, $\mathrm{HCW}$ s who have needle recapping behavior were 3.18 (AOR=3.18; $95 \%$ CI: 1.28, 8.83) more likely to be exposed to blood as compared with workers who do not recap needle (Table 5). HCWs who do not take HBV vaccination were $46 \%$ less likely to be exposed to blood as compared with their counterparts (AOR $=0.54 ; 95 \%$ CI: $0.12,0.78)$. HCWs who do not take IPPS training were also 13.53 more likely to be exposed to blood as compared with the others $(\mathrm{AOR}=13.53$; $95 \% \mathrm{CI}$ : 8.12, 19.11) (Table 5).

\section{Discussion}

The aim of this study was to assess occupational blood exposure and associated factors among HCWs in the Southern Tigrai zone governmental hospitals (Northern Ethiopia). The prevalence of lifetime occupational blood exposure was $46.5 \%$. This estimate was comparable with the report in Tanzania [17] where the prevalence was $48.6 \%$. In fact, this figure is lower than these reported in Iran (53.4\%), Serbia (60.6\%), Taiwan (71\%), and other part of Ethiopia (Bahirdar) (74\%) [13, 18-20]. On the contrary, our findings revealed a higher prevalence of blood exposure when compared with studies done in Kenya (25\%), India (32.7\%), and Hawassa (Ethiopia) (28\%) $[15,21,22]$. These differences might be subjected to variations in socio-economic, demographic, and cultural characteristics of the study participants, and health facility setups. Exclusion of blood-free body-fluids, in our study, could also contribute to the differences.

In this study, five key risk factors were found to have significant influence on the prevalence of exposure. HCWs who work for more than $40 \mathrm{~h}$ per week were more likely (about nine times) to experience blood exposure than others. This finding is consistent with the 
Table 4 Occupational blood exposure and related information among blood-exposed HCWs (N=148) in the Southern Tigrai zone governmental hospitals, Northern Ethiopia, 2020

\begin{tabular}{|c|c|c|c|c|}
\hline Variables & Category & & Frequency (n) & Percent (\%) \\
\hline \multirow[t]{2}{*}{ Needle stick injury } & No & & 94 & 63.5 \\
\hline & Yes & & 54 & 36.5 \\
\hline \multirow[t]{2}{*}{ Blood splash } & No & & 48 & 32.4 \\
\hline & Yes & & 100 & 67.6 \\
\hline \multirow[t]{2}{*}{ Sharp injury } & No & & 119 & 80.4 \\
\hline & Yes & & 29 & 19.6 \\
\hline \multirow[t]{22}{*}{ Place of exposure } & Emergency and injection & No & 119 & 80.4 \\
\hline & & Yes & 29 & 19.6 \\
\hline & Pediatrics ward & No & 142 & 97.2 \\
\hline & & Yes & 6 & 2.8 \\
\hline & Delivery ward & No & 101 & 68.2 \\
\hline & & Yes & 47 & 31.8 \\
\hline & Medical ward & No & 141 & 95.3 \\
\hline & & Yes & 7 & 4.7 \\
\hline & Surgical ward & No & 140 & 94.5 \\
\hline & & Yes & 8 & 5.5 \\
\hline & Operation theater unit & No & 108 & 73.0 \\
\hline & & Yes & 40 & 27.0 \\
\hline & Cleaner unit & No & 120 & 81.1 \\
\hline & & Yes & 28 & 19.9 \\
\hline & Laundry unit & No & 137 & 92.6 \\
\hline & & Yes & 11 & 7.4 \\
\hline & Laboratory unit & No & 134 & 90.5 \\
\hline & & Yes & 14 & 9.5 \\
\hline & OPD & No & 142 & 95.9 \\
\hline & & Yes & 6 & 4.1 \\
\hline & Other working room & No & 134 & 90.5 \\
\hline & & Yes & 14 & 9.5 \\
\hline \multirow[t]{3}{*}{ Time of exposure } & Day & & 80 & 25.2 \\
\hline & Night & & 55 & 17.3 \\
\hline & Both & & 12 & 3.8 \\
\hline \multirow[t]{2}{*}{ Report of the blood exposure } & No & & 83 & 56.1 \\
\hline & Yes & & 65 & 43.9 \\
\hline
\end{tabular}

OPD-Outpatient department

results obtained in Tehran (Iran), Addis Ababa, and Dessie (Ethiopia) [11, 23, 24]. Reasons might include stress, loss of concentration, and fatigue, which could increase the chance of professional error, risky behaviors, and hence poor compliance with the precautions.

Furthermore, the supply of adequate PPE was identified as an important factor related to occupational blood exposure. In our study, those HCWs who do not have adequate supply of PPE were 3.88 times more likely to be exposed to blood than those who have adequate supply of
PPE. This is worrying as $49.73 \%$ of the HCWs reported lack of PPE. Our results are comparable with the findings in Bahir Dar (Ethiopia) [13], which specifically reported that healthcare providers who did not wear PPE were 1.98 times more liable to blood and body fluids exposure than other workers who wore PPE. This is due to the fact that whenever there is lack of PPE supply, HCWs will not have the chance to use them in the healthcare settings while giving any medical care. Consequently, they will become more prone to blood exposure. 
Table 5 Bivariable and multivariable binary logistic regression analysis results of factors associated with occupational blood exposure among HCWs (N=318) in the Southern Tigrai zone governmental hospitals, Northern Ethiopia, 2020

\begin{tabular}{|c|c|c|c|c|c|c|}
\hline \multirow[t]{2}{*}{ Variables } & \multirow[t]{2}{*}{ Category } & \multicolumn{2}{|c|}{ Exposure status } & \multirow[t]{2}{*}{ COR $(95 \% \mathrm{Cl})$} & \multirow{2}{*}{$\begin{array}{l}\mathrm{p}- \\
\text { value }\end{array}$} & \multirow[t]{2}{*}{ AOR $(95 \% \mathrm{Cl})$} \\
\hline & & Yes (n) & No $(n)$ & & & \\
\hline \multirow[t]{7}{*}{ Profession } & Nurse & 50 & 67 & $2.61(1.44,4.21)$ & $0.04 *$ & $2.15(1.12,4.18)$ \\
\hline & Midwife & 31 & 23 & $3.01(2.01,6.51)$ & $0.05^{*}$ & $2.60(2.30,5.45)$ \\
\hline & Laboratory & 18 & 12 & $4.02(3.02,8.12)$ & $0.03^{*}$ & $3.15(1.43,9.60)$ \\
\hline & Cleaner & 22 & 24 & $3.31(1.33,6.35)$ & 0.24 & $1.84(1.11,5.16)$ \\
\hline & Laundry & 13 & 12 & $3.91(1.52,7.57)$ & 0.20 & $1.92(1.28,4.52)$ \\
\hline & Others & 2 & 11 & $0.81(2.52,8.57)$ & 0.25 & $0.72(0.25,0.84)$ \\
\hline & Medical doctor & 12 & 21 & 1 & & 1 \\
\hline \multirow[t]{2}{*}{ Level of the hospital } & Primary & 44 & 36 & $1.57(1.23,4.00)$ & $0.05^{*}$ & $1.22(0.62,3.34)$ \\
\hline & Secondary & 104 & 134 & 1 & & 1 \\
\hline \multirow[t]{2}{*}{ Working hours per week } & $\leq 40 \mathrm{~h}$ & 26 & 112 & 1 & & 1 \\
\hline & $>40 \mathrm{~h}$ & 122 & 58 & $9.06(6.13,12.52)$ & $0.00 *$ & $9.42(7.61,11.41)$ \\
\hline \multirow[t]{2}{*}{ Working time shift } & No & 92 & 84 & $1.68(1.15,4.80)$ & $0.03 *$ & $1.54(1.10,6.52)$ \\
\hline & Yes & 56 & 86 & 1 & & 1 \\
\hline \multirow[t]{2}{*}{ Additional responsibilities } & No & 89 & 128 & 1 & & 1 \\
\hline & Yes & 59 & 42 & $2.02(1.80,4.82)$ & $0.04^{*}$ & $2.52(1.85,6.96)$ \\
\hline \multirow[t]{2}{*}{ Adequate PPE supply } & No & 98 & 60 & $3.59(2.33,6.55)$ & $0.02 *$ & $3.88(1.64,5.42)$ \\
\hline & Yes & 50 & 110 & 1 & & 1 \\
\hline \multirow[t]{2}{*}{ Adequate safety box } & No & 64 & 41 & $3.08(2.22,5.62)$ & $0.04^{*}$ & $2.52(1.14,5.06)$ \\
\hline & Yes & 47 & 93 & 1 & & 1 \\
\hline \multirow[t]{2}{*}{ Needle recapping } & No & 60 & 114 & 1 & & 1 \\
\hline & Yes & 88 & 56 & $2.98(2.23,4.50)$ & $0.01 *$ & $3.18(1.28,8.83)$ \\
\hline \multirow[t]{2}{*}{ HBV vaccination status } & No & 41 & 59 & $0.72(0.12,0.82)$ & $0.00 *$ & $0.54(0.12,0.78)$ \\
\hline & Yes & 107 & 111 & 1 & & 1 \\
\hline \multirow[t]{2}{*}{ Proper waste segregation practice } & No & 33 & 22 & $1.93(1.52,1.74)$ & 0.23 & $1.93(1.41,6.21)$ \\
\hline & Yes & 115 & 148 & 1 & & \\
\hline \multirow[t]{2}{*}{ IPPS training } & No & 100 & 25 & $12.08(6.12,18.31)$ & $0.05^{*}$ & $13.53(8.12,19.11)$ \\
\hline & Yes & 48 & 145 & 1 & & 1 \\
\hline
\end{tabular}

${ }^{1}$ reference category, * Significant association ( $p$-value $<0.05$ ) for COR, COR-crude odds ratio, AOR-adjusted odds ratio, PPE- Personal protective equipment, IPPSInfection prevention and patient safety, HBV- Hepatitis B Virus

Our results also revealed that IPPS training and needle recapping behavior could significantly affect the prevalence of occupational blood exposure. Prevalence was shown to be 13.5 times higher in those who do not attend training courses. Respondents who practice needle recapping had also $318 \%$ more chance to experience exposure than those who do not recap needles after use. This implies the potential of on-job training in enhancing the skills of HCWs, and hence reducing job risks. Other studies conducted in Northeast Ethiopia [11], Southeast Ethiopia [12], Eastern Ethiopia [25], Southwest Ethiopia [26], and South Carolina [27] also reported the importance of IPPS training and needle recapping behavior in influencing occupational exposures.
Moreover, HCWs who take HBV vaccine were $54 \%$ more likely to be exposed to blood as compared with workers who do not take the vaccine. This is possibly associated with negligence and carelessness to avoid blood exposure as HCWs sometimes perceive that vaccination could increase their immunity to HBV. Similar findings were also reported from studies in Gondar (Northern Ethiopia) [9] and Cameroon [28]

\section{Limitations of the study}

This cross-sectional study was based on self-reported lifetime occupational blood exposure, and hence the results were possibly liable to social desirability and recall biases. 


\section{Conclusions}

The prevalence of lifetime blood exposure among HCWs in the Southern Tigrai zone governmental hospitals was $46.5 \%$. The main route of blood exposure was blood splash $(67.6 \%)$ followed by needle stick (36.5\%) and sharp (19.6\%) injuries. From the total respondents, $45.2 \%$ had needle recapping behavior and $68.6 \%$ had received HBV vaccination. Working for more than $40 \mathrm{~h}$ per week, lack of adequate PPE, HBV vaccination, recapping used needles, and lack of IPPS training were found to significantly increase the likelihood of occupational blood exposure. Therefore, reducing the work load, supplying adequate PPE, avoiding recapping of used needle sticks, and providing IPPS training for HCWs should be emphasized to reduce occupational blood exposure.

\begin{abstract}
Abbreviations
AOR: Adjusted odds ratio; ART: Antiretroviral Therapy; COR: Crude odds ratio; ETB: Ethiopian Birr; HCW: Healthcare worker; HBV: Hepatitis B virus; HCV: Hepatitis C virus; HIV: Human immunodeficiency virus; IPPS: Infection prevention and patient safety; $\mathrm{MCH}$ : Maternal and child health; OPD: Outpatient department; PPE: Personal protective equipment; TB: Tuberculosis; WHO: World Health Organization
\end{abstract}

\section{Supplementary information}

The online version contains supplementary material available at https://doi. org/10.1186/s12913-021-07167-9.

Additional file 1 Appendix A

\section{Acknowledgements}

The authors acknowledge Wollo University, college of medicine and health sciences for the financial support. We also acknowledge chief executiveofficers of the Southern Tigrai zone hospitals' for providing the necessary documents for the research work. Our gratitude also goes to the study participants and data collectors for their genuine cooperation.

\section{Authors' contributions}

SR, MG, and ML designed the study. SR, MG, AK, BW, and MA analyzed and interpreted data, and wrote the first draft of the manuscript. TCM, ML, CD, $A A$, and $A F$ supervised data collection and interpreted data. MG, AK, AF, and BW critically revised the manuscript. All authors read and approved the final manuscript.

\section{Funding}

No funding.

\section{Availability of data and materials}

Datasets analyzed during the current study are available from the corresponding author upon reasonable request.

\section{Declarations}

\section{Ethical approval and consent to participate}

All methods, including ethical approval and research permission, were performed in accordance with national standards, guaranteeing the anonymity of the respondents. The study was approved by the institutional review board of Wollo University, college of medicine and health sciences (WU/CMHS/1129/02/12). In addition, written consents were obtained from the coordinators of each hospital. Besides, respondents were informed about the purpose of the study, and their informed consent was obtained. The respondents' right to refuse or withdraw from participating in the study was fully maintained and the information provided by each respondent was kept strictly confidential.

\section{Consent for publication}

Not applicable.

\section{Competing interests}

The authors declare no competing interests.

\section{Author details}

${ }^{1}$ Department of Environmental Health, College of Medicine and Health Sciences, Wollo University, Dessie, Ethiopia. ${ }^{2}$ Department of Nutrition, School of Public Health, College of Medicine and Health Sciences, Wollo University, Dessie, Ethiopia.

Received: 22 March 2021 Accepted: 5 October 2021

Published online: 22 October 2021

\section{References}

1. Salmanzadeh S, Rahimi Z, Goshtasbipour M, Meripoor M: The prevalence of needle-stick injuries among healthcare workers in Dasht-e-Azadegan, southern west of Iran. International Journal of Pharmaceutical Research and Allied Sciences 2016, 5(2):417-422.

2. Kasatpibal N, Whitney JD, Katechanok S, Ngamsakulrat S, Malairungsakul B, Sirikulsathean P, Nuntawinit C, Muangnart T: Prevalence and risk factors of needlestick injuries, sharps injuries, and blood and body fluid exposures among operating room nurses in Thailand. American journal of infection control 2016, 44(1):85-90.

3. CDC: Centers for Disease Control and Prevention, Division of Health care Quality Promotion. Surveillance of Healthcare Personnel with HIV/AIDS. http:// www.cdc.gov/ncidod/dhqp/bp_hiv_hp_with.htm [accessed 27 Nov 2020]. 2020.

4. Auta A, Adewuyi EO, Tor-Anyiin A, Aziz D, Ogbole E, Ogbonna BO, Adeloye D: Health-care workers' occupational exposures to body fluids in 21 countries in Africa: systematic review and meta-analysis. Bulletin of the World Health Organization 2017, 95(12):831.

5. Saia M, Hofmann F, Sharman J, Abiteboul D, Campins M, Burkowitz J, Choe Y, Kavanagh S. Needlestick injuries: incidence and cost in the United States, United Kingdom, Germany, France, Italy, and Spain. Biomed Int. 2010;1(2): 41-9.

6. FMoH: 'Ethiopian Federal Ministry of Health, Hospital Reform Implementation Guidelines', 2010; 1(2), pp. 1-400. 2010.

7. Yazie TD, Chufa KA, Tebeje MG: Prevalence of needlestick injury among healthcare workers in Ethiopia: a systematic review and meta-analysis. Environmental health and preventive medicine 2019, 24(1):1-10.

8. Sahiledengle B, Tekalegn Y, Woldeyohannes D, Quisido BJE: Occupational exposures to blood and body fluids among healthcare workers in Ethiopia: a systematic review and meta-analysis. Environmental health and preventive medicine 2020, 25(1):1-14.

9. Yasin J, Fisseha R, Mekonnen F, Yirdaw K: Occupational exposure to blood and body fluids and associated factors among health care workers at the University of Gondar Hospital, Northwest Ethiopia. Environmental health and preventive medicine 2019, 24(1):1-9.

10. Sahiledengle B, Tekalegn Y, Woldeyohannes D: The critical role of infection prevention overlooked in Ethiopia, only one-half of health-care workers had safe practice: A systematic review and meta-analysis. PloS one 2021, 16(1): e0245469.

11. Kebede A, Gerensea H: Prevalence of needle stick injury and its associated factors among nurses working in public hospitals of Dessie town, Northeast Ethiopia, 2016. BMC research notes 2018, 11(1):1-6.

12. Bekele T, Gebremariam A, Kaso M, Ahmed K. Factors associated with occupational needle stick and sharps injuries among hospital healthcare workers in Bale Zone, Southeast Ethiopia. PloS one. 2015;10(10):e0140382.

13. Yenesew MA, Fekadu GA. Occupational exposure to blood and body fluids among health care professionals in Bahir Dar town, Northwest Ethiopia. Safety and health at work. 2014;5(1):17-22.

14. CSA: Ethiopian central statistical agency, population and census result. Addis Ababa. In.; 2007.

15. Kaweti G, Abegaz T. Magnitude of splash exposure and associated factors among health care workers in Hawassa referral and Adare District hospitals, January 2014. Annals of Occupational and Environmental Medicine. 2017; 29(1):1-7. 
16. CDC: Centers for Disease Control and Prevention, Communicable Disease Control and Blood and Body Fluid Exposure Management manual, 2017; pp. 1-22. 2017.

17. Chalya PL, Seni J, Mushi MF, Mirambo MM, Jaka H, Rambau PF, Kapesa A, Ngallaba SE, Massinde AN, Kalluvya SE: Needle-stick injuries and splash exposures among health-care workers at a tertiary care hospital in northwestern Tanzania. Tanzania Journal of Health Research 2015, 17(2).

18. Naderi H, Sheybani F, Bojdi A, Mostafavi I, Khosravi N. Occupational exposure to blood and other body fluids among health care workers at a university hospital in Iran. Workplace health \& safety. 2012;60(10):419-22.

19. Markovic-Denic L, Maksimovic N, Marusic V, Vucicevic J, Ostric I, Djuric D. Occupational exposure to blood and body fluids among health-care workers in Serbia. Medical Principles and Practice. 2015;24(1):36-41.

20. Ko N-Y, Yeh S-H, Tsay S-L, Ma H-J, Chen C-H, Pan S-M, Feng M-C, Chiang MC, Lee Y-W, Chang L-H. Intention to comply with post-exposure management among nurses exposed to blood and body fluids in Taiwan: application of the theory of planned behaviour. Journal of Hospital Infection. 2011;77(4):321-6.

21. Mbaisi EM, Wanzala P, Omolo J: Prevalence and factors associated with percutaneous injuries and splash exposures among health-care workers in a provincial hospital, Kenya, 2010. Pan African Medical Journal 2013, 14(1).

22. Singru SA, Banerjee A. Occupational exposure to blood and body fluids among health care workers in a teaching hospital in Mumbai, India. Indian journal of community medicine: official publication of Indian Association of Preventive \& Social Medicine. 2008;33(1):26.

23. Shokuhi S, Gachkar L, Alavi-Darazam I, Yuhanaee P, Sajadi M. Occupational exposure to blood and body fluids among health care workers in teaching hospitals in Tehran, Iran. Iranian Red Crescent Medical Journal. 2012;14(7): 402.

24. Feleke BE. Prevalence and determinant factors for sharp injuries among Addis Ababa hospitals health professionals. Sci J Public Health. 2013;1(5) 189-93.

25. Alemayehu T, Worku A, Assefa N. Medical waste collectors in eastern Ethiopia are exposed to high sharp injury and blood and body fluids contamination. Prev Inf Cntrl. 2016;2:2.

26. Belachew YB, Lema TB, Germossa GN, Adinew YM. Blood/body fluid exposure and needle stick/sharp injury among nurses working in public hospitals; Southwest Ethiopia. Frontiers in public health. 2017;5:299.

27. Doebbeling BN, Vaughn TE, McCoy KD, Beekmann SE, Woolson RF, Ferguson KJ, Torner JC. Percutaneous injury, blood exposure, and adherence to standard precautions: are hospital-based health care providers still at risk? Clinical Infectious Diseases. 2003;37(8):1006-13.

28. Nouetchognou JS, Ateudjieu J, Jemea B, Mbanya D. Accidental exposures to blood and body fluids among health care workers in a Referral Hospital of Cameroon. BMC research notes. 2016;9(1):1-6.

\section{Publisher's Note}

Springer Nature remains neutral with regard to jurisdictional claims in published maps and institutional affiliations.

Ready to submit your research? Choose BMC and benefit from:

- fast, convenient online submission

- thorough peer review by experienced researchers in your field

- rapid publication on acceptance

- support for research data, including large and complex data types

- gold Open Access which fosters wider collaboration and increased citations

- maximum visibility for your research: over $100 \mathrm{M}$ website views per year

At BMC, research is always in progress.

Learn more biomedcentral.com/submissions 